\title{
Correction to: Disappearance of Quorum Sensing in Burkholderia Glumae During Experimental Evolution
}

\section{Gopalsamy Gnanasekaran ${ }^{1}$ [D}

Published online: 9 May 2020

(C) Springer Science+Business Media, LLC, part of Springer Nature 2020

Correction to: Microbial Ecology (2020) 40:947-959 https://doi.org/10.1007/s00248-019-01445-0

Following the publication of this article [1], authors Jae Yun Lim and Ingyu Hwang have stated that they were not aware of, nor were they involved in the drafting, submission, or revision of this manuscript. Therefore, they should no longer be considered authors of this article.

\section{Reference}

1. Gnanasekaran G, Lim JY, Hwang I (2020) Disappearance of quorum sensing in Burkholderia glumae during experimental evolution. Microb Ecol 79:947-959. https://doi.org/10.1007/s00248-019$01445-0$

The online version of the original article can be found at https://doi.org/ 10.1007/s00248-019-01445-0

Gopalsamy Gnanasekaran gnanasekaran@snu.ac.kr

1 Department of Agricultural Biotechnology, College of Agriculture, and Life Sciences, Seoul National University, Seoul, Republic of Korea 